\title{
Research on Enterprise Financial Decision-making in Big Data Era
}

\author{
Liu Fang, Yang Shuyuan \\ Yunnan Normal University Business School, Yunnan, China 650101
}

Keywords: Financial decision-making; Big data era; Enterprise; Challenges; Countermeasures

Abstract: As an important part of enterprises 'production and operation activities, the effect of financial decision-making affects the development of enterprises. With the advent of the information age, big data has also brought tremendous challenges to the financial decision-making of enterprises. In order to provide better decision support for enterprise financial management, it first needs to understand what changes and impacts the big data environment has brought to enterprise financial decision-making, find out the opportunities and challenges in the process of applying big data at this stage, and put forward targeted measures for financial decision-making in the era of big data, so as to bring positive impact on the development of enterprise financial decision-making.

\section{Introduction}

At present, the amount of data in the world is growing on a large scale. Faced with the huge amount of data, how to obtain faster and more efficient information sources from various channels and excavate the value behind the information is a hot issue of general concern to the public, and also the key to timely financial decision-making by managers in the financial field. Financial decision-making is a decision-making process under the guidance of financial policies and financial programs. The purpose of its decision is to obtain a more satisfactory financial plan. Big data is the product of the development of the information age to a certain stage. In order to successfully carry out the financial decision-making work, it is necessary to play the powerful role of big data. From the process of data collection, data mining and data analysis, it can mine valuable financial decision-related information. .

\section{The impact of big data era on enterprise financial decision-making}

In today's big data era, the traditional financial decision-making model can no longer meet the needs of contemporary enterprise financial management. Faced with such complex and large-scale data information, enterprise leaders should keep up with the development trend of big data and actively explore the changes and impacts of big data on financial decision-making, so as to guide financial-related decision-making with big data strategic thinking mode to better serve customers and the public. 


\subsection{The impact on financial decision-making participants}

Traditional decision-making methods rely more on the experience accumulated by business managers over the years and rich management concepts. This judgment based on subjective consciousness has risks to a certain extent. Once the external environment changes, managers do not have enough time to deal with it, which may lead to the failure of decision-making and cause more or less losses to customers and enterprises themselves. In the era of big data, great changes have taken place in the thinking mode and decision-making framework of financial decision-making. Through collecting massive data, the next step can be processed and analyzed, and the indicators related to financial decision-making contained in the processed data can be extracted as a new standard for measuring financial decision-making, which helps enterprises to make appropriate scientific decisions.

\subsection{The impact on financial decision making tools}

In the era of big data, if an enterprise wants to win the first place among many competitors, it is necessary to guide its daily operation and management with correct and efficient financial decisions To make effective financial decisions, managers often need to build on a large number of data mining, effective data analysis and processing, which undoubtedly greatly improves the enterprise's financial management software measurement standards. Faced with the increasing variety of data types and the increasingly complex data structure of enterprise data, the financial analysis system and financial decision-making framework of enterprises are required to be constantly improved, and a large data analysis and processing platform is established to better use various financial tools to guide the financial decision-making of enterprises.

\subsection{The impact on enterprises financial decision-making}

Under the influence of big data era, the development of enterprise financial decision-making needs the management of internal organizational system to carry out various production and operation activities. Enterprises need to strengthen cost control. Through the data of cost management, the enterprise carries out in-depth and systematic analysis, understands the various links among data, and ensures the effectiveness of enterprise production and operation, which can fundamentally improve work efficiency and provide a good internal environment for enterprise financial decision-making. The development of enterprise financial decision-making is affected by the actual value of the enterprise, and the rationality of the fair value will also have a positive impact on the financial assets of the enterprise. Fair value is mainly reflected in the future discount data collection of cash flow to achieve the effective establishment of the fair value, and the slight changes in data will also have a certain impact on the determination of the fair value. Under the influence of big data era, financial decision-making of enterprises can ensure that financial staff carry out the analysis of fair value related data, and make full use of big data processing technology to determine the actual fair value of enterprise development, so as to promote the forward development of enterprise financial decision-making.

\section{Challenges for enterprise financial decision-making in big data era}

\subsection{Challenges on management models}

Due to the influence of traditional management mode, enterprises are difficult to adapt to the current situation of social development. For modern information technology management, it is 
difficult to fully apply to the actual financial decision-making of enterprises. Enterprises make financial decisions without innovative consciousness, and internal financial management system is confused, which leads to the traditional management mode cannot be improved, at the same time, it is difficult to meet the needs of modern information technology management, there is a significant gap between the two, the implementation of modern management system is difficult to reflect, which is very unfavorable to the development of enterprises.

\subsection{Challenges on financial management system}

Under the background of big data era, the perfection of financial management system is very important for enterprises to make better financial decisions. However, according to the current situation of enterprise financial decision-making, the financial management system is not perfect enough, the financial management mode is relatively single, the development of enterprise financial management is frequently hindered, and the coordination degree between various departments in enterprise internal management is not high, the application of enterprise financial decision-making is not strong, in the long run, will not be conducive to the promotion and use of enterprise decision-making.

\section{Countermeasures for enterprise financial decisions in big data era}

\subsection{Culltivate big data management awareness at the decision-making level}

The era characterized by big data management is coming. If enterprises are not aware of this change and cannot quickly identify risks and explore business opportunities from big data, they will inevitably be defeated gradually in the future industry competition. The greatest impetus for the renewal of enterprise ideology comes from the decision-making level's determination. Only by cultivating the awareness of big data management of enterprise decision-making level and strengthening organizational leadership, can we fundamentally establish the awareness of big data of enterprise. Enterprise managers can learn new knowledge about big data and financial decision-making, broaden new horizons, actively adapt to the financial decision-making mode in the era of big data, so that they can skillfully use big data and other analytical means to have a deep insight into the company's cash flow, resource allocation, risk management and control, and then put forward decision-making suggestions to allocate resources to the fast-growing field, and create greater value for the enterprise.

\subsection{Construct a scientific financial decision-making system}

In order to establish a scientific decision-making system of large data financial management, an effective financial decision-making process based on large data should be established according to the actual situation of enterprises. In order to change the mode of decision-making relying more on management experience in the past, we should actively collect relevant data of enterprises, establish a large data platform, collect, process and extract information from hundreds of thousands or even billions of data by using advanced technology, excavate the relevance behind the problems, explore the hidden risks and business opportunities of the enterprise, find out the solution to the problem, and achieve the purpose of leading the decision by the data.

\subsection{Improve the data quality related to financial decision-making}

The amount of information contained in the data goes beyond the scope of data processing 
ability of general business managers. It not only increases the workload of processing information, but also makes it difficult for traditional data management and data analysis techniques to effectively mine the potential value of these data, which leads to the difficulty of judging the value of the information. Only by building a new and powerful enterprise management decision-making system based on big data technology, can enterprises better collect, screen, classify and screen valuable data, which is conducive to more scientific decision-making.

\section{Conclusions}

With the advent of the era of big data, the explosive growth of data has made it necessary for corporate financial managers not only to consider the financial data of the grassroots, but also to measure the relationship between non-financial data and financial decisions. Therefore, as the key of enterprise financial management, financial decision-making must comply with the requirements of the new environment under big data, rely on information technology to collect relevant decision-making data, actively innovate enterprise financial decision-making mode, and fully integrate all data needed in enterprise financial decision-making by using big data technology, so as to ensure the rationality of enterprise financial decision-making.

\section{References}

[1] Cheng Ping, Zhao Zixiao. The impact of big data on enterprise financial decision[J]. Finance and Accounting, 2014 (10): 52-53.

[2] Huang Ziyu. Research on enterprise financial decision-making in big data era[J]. Accounting Learning, 2017, (02): 81.

[3] Gao Junyun. Research on enterprise financial decision-making in the age of big data and cloud accounting[J]. Modern Marketing, 2018 (1): 238. 